\title{
XXV.-The Triazo-group. Part VII. Interaction of Benzhydroximic Chloride and Sodium Azide.
}

\section{By Martin Onslow Forster.}

BeARING in mind the tendency displayed by the nitrogen atoms of the triazo-complex to undergo rearrangement, it seemed possible that benzhydroximic azide might be transformed into the isomeric tetrazole derivative by the influence of light or of some catalytic agent:

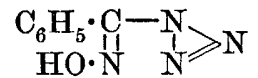

Benzhydroximic Azide $\left.\rightarrow \quad \begin{array}{c}\mathrm{C}_{6} \mathrm{H}_{5} \cdot \stackrel{\mathrm{C}}{\mathrm{C}}=\mathrm{N} \\ \mathrm{HO} \cdot \mathrm{N}-\mathrm{N}\end{array}\right\rangle \mathrm{N}$

1-Hydroxy-5-phenyltetrazole

On attempting to prepare the first-named compound by the interaction of benzhydroximic chloride and sodium azide, however, the product was found to have properties indicating the tetrazole derivative rather than the substituted azoimide, and it must be concluded that the ethenoid linking of the benzhydroximic nucleus is endowed with sufficient residual affinity to effect the redistribution represented above independently of external chemical agency.

The problem of deciding the claims of the above formulæ to represent the product of interaction between benzhydroximic chloride and sodium azide is not difficult, although the behaviour of the substance towards sulphuric acid, stannous chloride, or sodium hydroxide might be construed in favour of either representation. The action of concentrated sulphuric acid leads to mild detonation and charring, whilst the diluted agent liberates one-half the nitrogen, a result which might be expected from benzhydroximic azide; the same proportion of gas is evolved when the substance is treated with stannous chloride in hydrochloric acid, whilst hot alkali hydroxide yields a quantity somewhat in excess of one-half the total nitrogen, a result most likely due to the production of nitrous oxide. Such behaviour, accompanied as it is by the formation of benzonitrile, clearly supports the tetrazole structure,

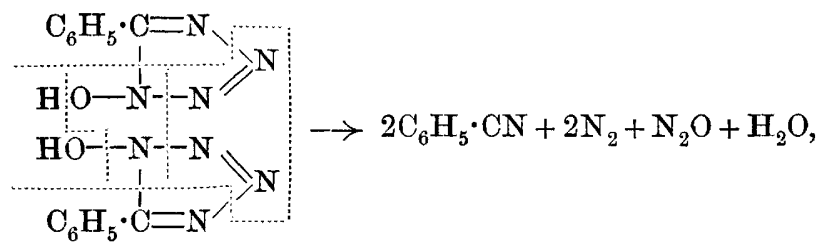

although it might be urged, on the other hand, that the decomposition was preceded by transformation of the azoimide into the tetrazole. 
The most convincing exclusion of the triazo-group, however, is furnished by comparison of the material with benzhydroximic chloride itself (Werner and Buss, Ber., 1894, 27, 2193). A solution of the latter substance in alcohol becomes turbid immediately when treated with silver nitrate, the turbidity rapidly intensifying to a precipitate of silver chloride when the liquid is warmed; benzhydroximic azide would be expected to yield silver azide in similar circumstances, and the non-formation of this compound seems crucial. Moreover, when alkali hydroxide acts on benzhydroximic chloride, two courses, both distinct from the one already indicated in connexion with the substance under discussion, are followed, each one depending on elimination of hydrogen chloride, which is accompanied either by benzildioxime peroxide, or by benzhydroxamic acid :

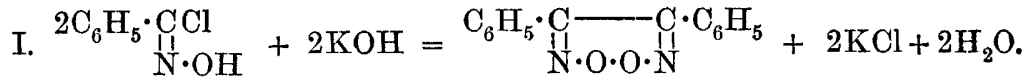

II.

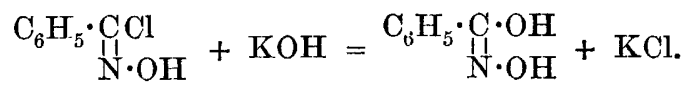

The absence of alkali azide from the products of decomposing the supposed hydroxyphenyltetrazole with potassium hydroxide is, therefore, highly significant. Furthermore, in presence of dilute alkali, it is possible to obtain well-defined benzoyl, $p$-toluenesulphonyl, and $\beta$-naphthalenesulphonyl derivatives, which could not be expected from benzhydroximic azide.

The transformation of benzhydroximic chloride into hydroxyphenyltetrazole recalls the experiments of Thiele (Annalen, 1892, 270, 1) with "diazoguanidine." This compound, obtained as a nitrate on adding sodium nitrite to a solution of aminoguanidine nitrate in nitric acid, was recognised subsequently by Hantzsch and Vagt (Annalen, 1901, 314, 339) as carbaminoiminoazoimide,

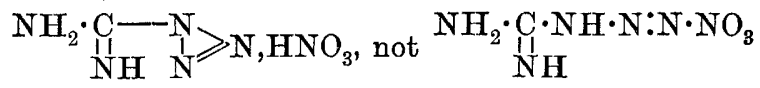

Thiele found that although alkali hydroxides resolve carbaminoiminoazoimide into cyanamide and hydrazoic acid, alkali carbonates effect a simple rearrangement of the atoms into aminotetrazole, a transformation realised also by dilute acids, although accompanied in this case by elimination of hydrazoic acid :

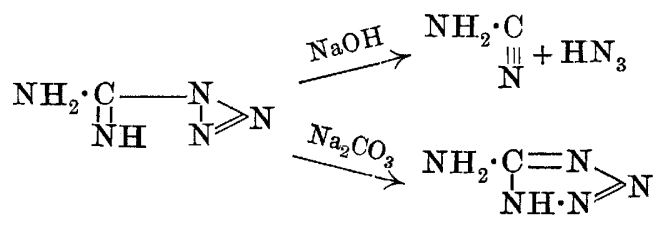

Comparing the relative position of the triazo-group and azethenoid 
linking with the situation of the amino-radicle in carbaminoiminoazoimide on the one hand, and with that of the phenyl complex in benzhydroximic azide on the other, it will be recognised that exact analogy prevails, whence the production of hydroxyphenyltetrazole is readily understood.

A somewhat similar, although not strictly analogous, instance of tetrazole formation was brought to light quite recently by Dimroth and Merzbacher (Ber., 1907, 40, 2402), who found that under the influence of sodium ethoxide, $1: 3$-diphenyltetrazole arises from phenylazoimide and benzylidenephenylhydrazone, with removal of aniline :

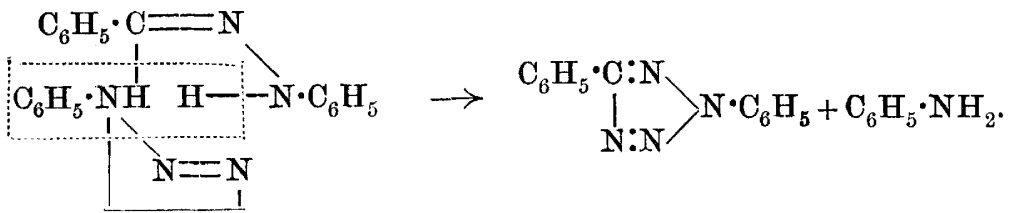

In this case, however, the triazo-group loses one atom of nitrogen, whereas the tetrazole-formation occurring when benzhydroximic chloride acts on sodium azide is the outcome of affinity rearrangement unaccompanied by loss of material.

\section{EXPERIMENTAL.}

$$
\text { 1-Hydroxy-5-phenyltetrazole, } \begin{gathered}
\mathrm{C}_{6} \mathrm{H}_{5} \cdot \underset{1}{\mathrm{C}: \mathrm{N}} \\
\mathrm{HO} \cdot \mathrm{N} \cdot \mathrm{N}
\end{gathered} \geqslant \mathrm{N} \text {. }
$$

Benzhydroximic chloride was prepared according to the directions of Werner and Buss (Ber., $1894,27,2197)$, and melted at $52^{\circ}$ after being twice recrystallised from light petroleum. Either the substance itself, or some impurity retained tenaciously by it, has an intensely disagreeable effect on the skin, which becomes attacked by an irritating rash; this outbreak not only persists during several days, but is liable to affect parts of the body not brought into direct contact with the material.

In order to convert the chloro-compound into the tetrazole, a 10 per cent. ethereal solution containing slight excess of the calculated amount of powdered sodium azide in suspension was allowed to remain at the laboratory temperature during two or three days, a few grams of dehydrated sodium sulphate having been previously added for the purpose of checking, by exclusion of moisture, any tendency towards elimination of hydrogen chloride and consequent liberation of hydrazoic acid. The filtered solution having been quickly evaporated by a current of dry air, the colourless residue was recrystallised without delay from hot petroleum (b. p. $60-80^{\circ}$ ), of which about 200 c.c. are required by one gram; as the product is liable to undergo decomposi- 
tion if left in the mother-liquor longer than one hour, it was precipitated by cooling, when the lustrous, transparent, snow-white needles were found to melt at about $124^{\circ}$, with vigorous intumescence :

$$
\begin{gathered}
0.0837 \text { gave } 25.2 \text { c.c. } \mathrm{N}_{2} \text { at } 18^{\circ} \text { and } 764 \mathrm{~mm} \text {. } \mathrm{N}=34.96 . \\
\mathrm{C}_{7} \mathrm{H}_{6} \mathrm{ON}_{4} \text { requires } \mathrm{N}=34.57 \text { per cent. }
\end{gathered}
$$

Although more than $\mathbf{5 0}$ grams of the substance have been obtained in this manner, it is not advisable to transform a greater quantity than 5 or 10 grams of the benzhydroximic chloride at one operation, because the tetrazole is a short-lived compound, and even when purified undergoes spontaneous decomposition within three days, leaving a residue of benzonitrile, and liberating gas which contains a certain proportion of nitric oxide ; this alteration takes place irrespective of environment, specimens behaving in the same way whether exposed to, or protected from, light, either in air, an acid-desiccator, an alkali-desiccator, or in one containing both acid and alkali.

Hydroxyphenyltetrazole is freely soluble in cold acetone, ethyl acetate, or ethyl alcohol, crystallising from the last-named in lustrous, transparent prisms on dilution with water; it is readily soluble in hot chloroform, from which it clystallises in needles on immediate cooling, but if the mother-liquor remains warm during a few minutes succeeding filtration, it becomes pale brown, and deposits benzonitrile alone on evaporation. The alcoholic solution does not precipitate sodium azide when treated with silver nitrate even on boiling, but it reduces an ammoniacal solution of silver oxide. Unlike benzhydroxamic acid, the tetrazole does not develop colour with ferric chloride.

Spontaneous Decomposition.-Seventeen grams of hydroxyphenyltetrazole which had not been recrystallised were allowed to undergo spontaneous decomposition, taking the form of vigorous intumescence accompanied by liquefaction; the escaping gas appeared to be nitrogen mixed with nitric oxide, and in view of the behaviour of the substance towards alkali it is probable that nitrous oxide also was present. Hydrazoic acid, hydrazine, hydroxylamine, and ammonia were not produced. The pale yellow liquid residue weighed 11 grams, consisting of benzonitrile and water; the nitrile boiled steadily at $188^{\circ}$ under $760 \mathrm{~mm}$. pressure, and as the result of a test with phenylhydrazine was evidently free from benzaldehyde. Hydroxyphenyltetrazole does not explode when heated, but the rush of gas at the melting point is very violent.

Action of Alkalis.-Hydroxyphenyltetrazole is insoluble in ammonia and in sodium carbonate, but alkali hydroxides dissolve it readily, and when the solution is gently warmed, vigorous effervescence takes place, followed by separation of benzonitrile. On decomposing one 
gram of the substance and removing the nitrile with ether, the alkaline liquid was indifferent towards Fehling's solution even when boiled, and did not give evidence of the presence of alkali nitrite or azide. The presence of nitrous oxide in the escaping gas was suspected, however, because quantitative examination gave on each occasion a result in excess of that which would be expected if one-half the nitrogen content appeared in elemental form :

\section{$0 \cdot 1934$ gave 34.7 c.c. $\mathrm{N}_{2}$ at $18^{\circ}$ and $761 \mathrm{~mm} . \quad \mathrm{N}=20 \cdot 75$. $\mathrm{C}_{7} \mathrm{H}_{8} \mathrm{ON}_{4}$ requires $\frac{1}{2} \mathrm{~N}=17 \cdot 26$ per cent.}

The experiments, of which the foregoing is an example, were conducted with 50 per cent. potassium hydroxide, but with a concentration of 10 per cent. it is easy to recognise the formation of a crystalline potassium derivative, which undergoes decomposition with rise of temperature.

Decomposition with Stannous Chloride.-The behaviour of the tetrazole derivative towards stannous chloride in hydrochloric acid is that which would have been anticipated from benzhydroximic azide:

0.2017 gave $29 \cdot 1$ c.c. $\mathrm{N}_{2}$ at $17^{\circ}$ and $761 \mathrm{~mm}$. $\mathrm{N}=16.76$.

$\mathrm{C}_{7} \mathrm{H}_{6} \mathrm{ON}_{4}$ requires $\frac{1}{2} \mathrm{~N}=17 \cdot 26$ per cent.

The liberation of gas is regular, and benzonitrile does not appear.

Action of Sulphuric Acid.-The tetrazole does not dissolve in cold, dilute sulphuric acid, but, when added to the concentrated agent, is immediately decomposed, evolving gas with mild detonation and charring, unless the substance is introduced, a few crystals at a time, into the vigorously shaken acid; nitric oxide and hydrazoic acid could not be detected, and the only recognised product besides nitrogen was benzoic acid, which separated in crystals on diluting the liquid. Owing to the violence of the action it was necessary to dilute the acid with half its volume of water for the purpose of gasometric experiments, and with this concentration the removal of nitrogen was not completed even on raising the temperature :

$0 \cdot 2070$ gave $29 \cdot 7$ c.c. $\mathrm{N}_{2}$ at $18^{\circ}$ and $760 \mathrm{~mm} . \quad \mathrm{N}=16.57$.

$\mathrm{C}_{7} \mathrm{H}_{6} \mathrm{ON}_{4}$ requires $\frac{1}{2} \mathrm{~N}=17 \cdot 26$ per cent.

The liquid, when rendered alkaline, did not reduce Fehling's solution.

\section{Derivatives of Hydroxyphenyltetrazole.}

The benzoyl derivative, $\begin{array}{r}\mathrm{C}_{6} \mathrm{H}_{5} \cdot \mathrm{CO} \cdot \mathrm{O} \cdot \mathrm{O} \cdot \mathrm{N} \cdot \mathrm{N} \\ \mathrm{H}_{5} \cdot \mathrm{N}\end{array} \geqslant \mathrm{N}$, was obtained from benzoyl chloride and an alkaline solution of the potassium derivative; it is moderately soluble in boiling alcohol, from which it crystallises in lustrous, snow-white needles: 
$0 \cdot 1500$ gave $27 \cdot 4$ c.c. $\mathrm{N}_{2}$ at $16^{\circ}$ and $763 \mathrm{~mm} . \quad \mathrm{N}=21 \cdot 38$.

$\mathrm{C}_{14} \mathrm{H}_{10} \mathrm{O}_{2} \mathrm{~N}_{4}$ requires $\mathrm{N}=21.05$ per cent.

The substance dissolves very sparingly in boiling petroleum, from which it separates in stellate aggregates; the melting point is $127^{\circ}$, when decomposition takes place.

The p-toluenesulphonyl derivative,

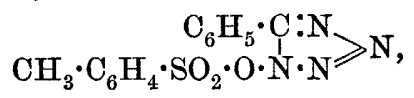

prepared by shaking 1 gram of the tetrazole dissolved in 5 per cent. potassium hydroxide with 3 grams of $p$-toluenesulphonyl chloride in 10 c.c. of ether, until the aqueous liquid no longer yielded benzonitrile and nitrogen when boiled, crystallised from light petroleum in transparent, rhomboidal prisms :

0.1108 gave 16.8 c.c. $\mathrm{N}_{2}$ at $14^{\circ}$ and $767 \mathrm{~mm} . \quad \mathrm{N}=18.01$.

$$
\mathrm{C}_{14} \mathrm{H}_{12} \mathrm{O}_{3} \mathrm{~N}_{4} \mathrm{~S} \text { requires } \mathrm{N}=17.72 \text { per cent. }
$$

The substance melts and evolves gas at $91-92^{\circ}$, and is scarcely soluble in cold petroleum. The first attempt to prepare it was made in presence of sodium carbonate instead of potassium hydroxide, and the only product was benzonitrile.

In the case of the $\beta$-naphthalenesulphonyl derivative,

$$
\begin{array}{r}
\mathrm{C}_{6} \mathrm{H}_{5} \cdot \mathrm{C}: \mathrm{N} \\
\mathrm{C}_{10} \mathrm{H}_{7} \cdot \mathrm{SO}_{2} \cdot \mathrm{O} \cdot \mathrm{N} \cdot \mathrm{N}
\end{array} \geqslant \mathrm{N}
$$

also, interaction between the sulphonyl chloride and the tetrazole was too sluggish in presence of sodium carbonate, and benzonitrile was formed; in presence of alkali hydroxide, however, union was complete in a few minutes, and the product was obtained on evaporating the ether :

$0 \cdot 1507$ gave $21 \cdot 3$ c.c. $\mathrm{N}_{2}$ at $21^{\circ}$ and $768 \mathrm{~mm} . \quad \mathrm{N}=16 \cdot 27$.

$$
\mathrm{C}_{17} \mathrm{H}_{12} \mathrm{O}_{3} \mathrm{~N}_{4} \mathrm{~S} \text { requires } \mathrm{N}=15.91 \text { per cent. }
$$

The substance dissolves readily in hot, absolute alcohol, crystallising in lustrous needles, which melt and decompose at $101^{\circ}$.

\section{Unsuccessful Attempt to Prepare an Allotropic Form of Nitrogen.}

Previous workers have been attracted by the possibility of liberating nitrogen from hydrazoic acid or its salts in such circumstances as to avoid the disintegration of the triazo-complex and to produce the element in the form of triazo-azoimide,<smiles></smiles>

in which the univalent triazo-group is combined with itself. Szarvasy (Trans., 1900, 77, 603), for example, electrolysed_hydrazoic acid and 
sodium azide in aqueous solutions of different concentration, obtaining hydrogen, nitrogen, and traces of ammonia; oxidation products of nitrogen did not arise, and although a slight deficiency of nitrogen seemed to indicate some condensation to a polymeric form, determination of density failed to confirm the suggestion. Oxidation of hydrazoic acid by means of potassium permanganate also results in disrupting the triazo-group, but the process has been shown untrustworthy for the gasometric estimation of azoimide (Dennis and Browne, J. Amer. Chem. Soc., 1904, 26, 577).

It seemed possible, however, that the analogy subsisting between the triazo-complex and the halogens, particularly iodine, might be carried so far as to permit realisation of the following change:

$$
\begin{aligned}
\mathrm{C}_{6} \mathrm{H}_{5} \cdot \mathrm{NCl} \cdot \mathrm{CO} \cdot \mathrm{CH}_{3}+2 \mathrm{NaN}_{3}+\mathrm{H}_{2} \mathrm{O}= \\
\qquad \mathrm{C}_{6} \mathrm{H}_{5} \cdot \mathrm{NH} \cdot \mathrm{CO} \cdot \mathrm{CH}_{3}+\mathrm{N}_{6}+\mathrm{NaCl}+\mathrm{NaOH} .
\end{aligned}
$$

Accordingly, the action of phenyl acetyl nitrogen chloride on sodium azide was studied under various conditions, with the uniform result that although, in presence of water, liberation of gas occurred, the volume indicated the production of $3 \mathrm{~N}_{2}$ unmixed with $\mathrm{N}_{6}$; a solution of the nitrogen halide in dry ether was without action on sodium azide, the substances being recovered unchanged after an interval of five weeks. Perhaps, however, it is well that the attempt to prepare $\mathrm{N}_{6}$ was not successful, because there is every probability that this form of the element would be highly dangerous; it may even be the case that the alarming explosion which occurred after distilling unsymmetrical bistriazoethane (Trans., 1908, 93, 1073) originated in liberation of $\mathrm{N}_{6}$, production of the element in this modification being favoured by the attachment of both triazo-groups to a single atom of carbon. Although the original object of the experiment was not fulfilled, it is possible that the change recorded may form the basis of a method for the quantitative estimation of sodium azide. If interaction takes place in aqueous acetone, the liberation of gas is much more rapid than when the solid phenyl acetyl nitrogen chloride is suspended in aqueous sodium azide, and in less than one hour falls short of the theoretical amount by only 4 or 5 per cent., but the reaction does not appear to be complete even when some excess of the halogen compound is used, since the residual liquid was found to contain sodium azide. Attempts will be made to devise a process by which a weighed quantity of the salt may be led to yield all its nitrogen in elemental form.

Since the completion of the experiments described in this paper, there has appeared a description of the remarkable chloride of azoimide, $\mathrm{Cl} \cdot \mathrm{N}_{3}$ (Raschig, Ber., 1908, 41, 4194), and the method by which this compound was obtained, considered in regard to the action 
FORSTER AND MÜLLER: THE TRIAZO-GROUP. PART VIII. 191

between aqueous sodium azide and phenyl acetyl nitrogen chloride, has a bearing on the mechanism of the change which takes place when the last-named substance liberates iodine from hydrogen iodide. It has been supposed that, when the substituted nitrogen chloride undergoes hydrolysis leading to replacement of chlorine by hydrogen, the halogen escapes in the form of hypochlorous acid (compare Chattaway and Wadmore, Trans., 1902, 81, 199), but in that case the action of phenyl acetyl nitrogen chloride on aqueous sodium azide should have led to the production of Raschig's chloroazoimide, since that compound arises on acidifying a mixture of sodium hypochlorite and azide with boric or acetic acid. As the nitrogen was, in one set of experiments, collected over potassium hydroxide, in which Raschig has shown the chloroazoimide to be soluble and to regenerate hypochlorite and azide, it would seem that, in this case, at any rate, the action of phenyl acetyl nitrogen chloride in water is distinct from that of hypochlorous acid.

Royal College of Science, London, South Kensington, S. W. 